\title{
Analgesic and nonanalgesic effects of intravenous hydromorphone - Relation to plasma concentrations in healthy volunteers
}

\author{
D Westerling MD PhD, H Björk MSc, P Svedman MD PhD, P Höglund MD PhD
}

\begin{abstract}
D Westerling, H Björk, P Svedman, P Höglund.
Analgesic and nonanalgesic effects of intravenous hydromorphone - Relation to plasma concentrations in healthy volunteers.

Pain Res Manage 1996;1(2):86-92.
\end{abstract}

OBJECTIVE: To investigate the analgesic and nonanalgesic effects and the pharmacokinetics of an intravenous infusion of 2 mg hydromorphone over 20 mins.

DESIGN: Open study.

SUBJECTS: Twelve healthy volunteers.

MEASUREMENTS: The analgesic effect of hydromorphone was evaluated serially using pressure pain thresholds (PPTs) measured on the third fingers and toes. The nonanalgesic effects of hydromorphone were measured as miosis, decrease of saliva production and central nervous effects such as euphoria/dysphoria, nausea, headache, fatigue and feeling of heaviness. Plasma concentration of hydromorphone was measured using high performance liquid chromatography.

RESULTS: PPTs were significantly increased compared with baseline levels for up to $2 \mathrm{~h}$ after the infusion of hydromorphone. Significant miosis and reduction of saliva production were registered up to $6 \mathrm{~h}$ after drug administration. Fatigue and heaviness were reported by all subjects. In the studied opioid-naive subjects, the hydromorphone-induced analgesic effect was of shorter duration than the studied nonanalgesic effects. The terminal elimination half-life of hydromorphone was $1.87 \pm 0.4 \mathrm{~h}( \pm \mathrm{SD})(95 \% \mathrm{CI} 1.61$ to 2.13$)$, systemic clearance was $1.81 \pm 0.25 \mathrm{~L} / \mathrm{min}(95 \% \mathrm{CI} 1.65$ to 1.97 ) and volume of distribution was $4.15 \pm 0.86 \mathrm{~L} / \mathrm{kg}(95 \%$ CI 3.6 to 4.71 ).

CONCLUSION: Analgesia and nonanalgesic effects appear to be well correlated with the plasma concentrations of the hydromorphone.

Key Words: Intravenous hydromorphone, Nonanalgesic effects, Pharmacokinetics, Pressure pain thresholds

\section{Effets analgésiques et non analgésiques de l'hydromorphone intraveineux - Lien avec les concentrations plasmatiques chez des volontaires sains}

OBJECTIF : Investiguer les effets analgésiques et non analgésiques et la pharmacocinétique d'une perfusion intraveineuse de $2 \mathrm{mg}$ d'hydromorphone sur une période de 20 minutes.

MODÈLE : Étude ouverte.

SUJETS : Douze volontaires sains.

MESURES : L'effet analgésique de l'hydromorphone a été évalué en séries en utilisant les seuils de la douleur à la pression mesurés sur le majeur et le gros orteil. Les effets non analgésiques de l'hydromorphone ont été mesurés en tant que myosis, diminution de la production de salive et effets du système nerveux central tels l'euphorie ou la dysphorie, la nausée, les céphalées, la fatigue et la sensation de lourdeur. La concentration plasmatique d'hydromorphone a été mesurée par chromatographie haute performance.

RÉSULTATS : Les seuils de la douleur à la pression augmentaient considérablement comparativement aux valeurs de base jusqu'à deux heures après la perfusion d'hydromorphone. Un myosis important ainsi qu'une diminution de la production de salive ont été enregistrés jusqu'à $6 \mathrm{~h}$ après l'administration du médicament. La fatigue et la sensation de lourdeur ont été rapportées par tous les sujets. Dans le groupe étudié de sujets naïfs à l'opioïde, l'effet analgésique induit par l'hydromorphone persistait moins longtemps que les effets non analgésiques étudiés. La demi-vie d'élimination finale de l'hydromorphone était de $1,87 \pm 0,4 \mathrm{~h}$ (土écart-type) (IC $95 \%$ 1,61-2,13), la clairance systémique était de $1,81 \pm 0,25 \mathrm{~L} /$ minute (IC $95 \% 1,65-1,97$ ) et le volume de distribution de 4,15 $\pm 0,86 \mathrm{~L} / \mathrm{kg}$ (IC $95 \% 3,6-4,71$ ).

CONCLUSION : L'analgésie et les effets non analgésiques semblent corréler avec les concentrations plasmatiques de l'hydromorphone.

Department of Anesthesiology, Clinical Pharmacology and Plastic and Reconstructive Surgery, University of Lund, Lund, Sweden

Correspondence and reprints: Dr D Westerling, Department of Anesthesiology, Lund University Hospital, S-221 85 Lung, Sweden. Telephone 011-46-46-17-19-49, fax 011-46-46-14-23-30

Received for publication December 27, 1995. Accepted February 14, 1996 
$\mathrm{M}$ oderate to severe pain associated with malignant disease is often treated with morphine in combination with nonopioid analgesics (1). Side effects of morphine, such as myoclonus and hyperalgesia, may become a problem during long term treatment with moderate to large doses (2-4), and in some patients a change of opioid is necessary (5).

Hydromorphone is an opioid structurally similar to morphine; the main difference is the ketone group at position 6 in hydromorphone, which substitutes for a hydroxyl group at the same position in the morphine molecule (6). Hydromorphone is a high clearance drug (7) with a high affinity for mu opioid receptors (8), which is also reflected in a high analgesic potency in vivo. The drug is claimed to be seven to eight times more potent than morphine (6), although some investigators report lower (five times) (9) and some higher (10 to 12 times) (10,11) potency ratios.

Hydromorphone may thus be an interesting alternative to the high doses of morphine (12) that may be necessary during treatment for terminal cancer pain $(13,14)$.

Opioids have been used in intravenous, patient-controlled analgesia after coronary bypass surgery (15), subcutaneous infusion $(13,16)$ and oral administration (17) in patients suffering from severe pain due to malignant disease. In patients with unacceptable side effects of morphine, such as hyperalgesia and myoclonus (3), hydromorphone may be a beneficial alternative. However, hydromorphone therapy may also be associated with myoclonus $(18,19)$.

Although plasma concentrations of hydromorphone have been studied in humans using high performance liquid chromatography (HPLC) (7) and radioimmunoassay methods $(12,20)$, little is reported about the relationship between concentrations and pharmacodynamic effects of the drug.

The main aims of the present study were to investigate the analgesic and nonanalgesic effects of hydromorphone systematically. A further aim was to evaluate the possible relation between effects and plasma concentrations of the drug measured by HPLC. The analgesic effect of hydromorphone was studied using pressure pain thresholds (PPTs). Nonanalgesic effects of hydromorphone, often encountered as side effects during opioid therapy, namely dryness of the mouth, miosis, fatigue, nausea, euphoria/dysphoria, headache and the feeling of heaviness, were assessed.

\section{SUBJECTS}

Twelve healthy volunteers, seven men and five women, aged 23 to 40 years with a mean $( \pm \mathrm{SD})$ weight of $70.5 \pm 8.4 \mathrm{~kg}$ participated in the study after giving their written informed consent. Subjects were all well known to the investigators and were found to be healthy in a prestudy examination which included physical examination and blood and urine chemistry.

Exclusion criteria for participation in the study were known intolerance for opioids and other conditions, such as poor compliance or a history of drug or alcohol abuse, which, in the opinion of the investigators, would render the subject unsuitable.

The study was approved by the Ethics Committee of the University of Lund, Lund, Sweden and by the Swedish Medical Products Agency.

\section{METHODS}

After an overnight fast, subjects received an intravenous infusion of $2 \mathrm{mg}$ hydromorphone hydrochloride $(6.22 \mu \mathrm{mol}$ hydromorphone hydrochloride, Apoteksbolaget; Umeå, Sweden) over $20 \mathrm{mins}$ in an antecubital vein. Motor driven syringes (Terumo syringe pump STC-521; Vingmed Svensha AB, Stockholm, Sweden, or IVAC model 770; MDD Scandinavia AB, Täby, Sweden) were used to deliver the dose.

Venous blood samples were drawn from a short indwelling catheter in a contralateral arm vein before the infusion and at 5 , $10,20,25,30$ and $45 \mathrm{mins}$, and at $1,1.3,1.7,2.17,3.17,4.17$, $5.17,6.17,8.17,11.17,14.17,24.17,30.17,48.17$ and $72.17 \mathrm{~h}$ after the start of the infusion.

Subjects had a light lunch $4 \mathrm{~h}$ after drug administration, dinner after $8 \mathrm{~h}$ and a light meal after $12 \mathrm{~h}$.

Oxygen saturation was recorded using a pulse oxymeter (Oxicap 4700; Ohmeda, Kentucky) with a finger probe at the same time as the blood samples were drawn (up to $14 \mathrm{~h}$ after hydromorphone was given). Fatigue, euphoria, dysphoria, headache, nausea and the feeling of heaviness were evaluated using category ratio scales $(21-23)$ at the same time that blood samples were drawn (up to $30 \mathrm{~h}$ after drug administration).

Pupil size, PPTs and saliva production were measured before the infusion and serially over $24 \mathrm{~h}$ after the start of the infusion.

\section{MEASUREMENTS}

Unstimulated salivation was measured by the method described by Heinize et al (24). Two measurements were made before drug administration and at regular intervals during the procedure. Subjects were asked to spit into a preweighed plastic cup for 5 mins. The cup was then weighed. The mean of the two predrug measurements was considered to be baseline saliva production.

Each subject's right eye was photographed under standardized conditions before and at regular intervals after hydromorphone administration. The diameters of the pupil and the iris were measured on the negative film and the pupil:iris diameter ratio was calculated (23). The ratio was chosen to ascertain that the measurements were made in the same frontal plane.

Category rating scales with ratio properties, according to principles of Borg (21) and Borg et al (22), and previously used $(23,25)$, were employed to evaluate feelings of fatigue, euphoria/dysphoria, headache, heaviness and nausea. The scale ranged from 'nothing at all' to 'maximal'. Other labels were spaced nearly linearly, whereas the scale from 0.1 to 10 was logarithmic (26). At each test subjects were shown a new scale for each of the studied variables and were asked to select the appropriate magnitude of the sensation.

PPTs were measured using an algometer (Somedic AB, Sollentuna, Sweden). Measurements were made using the stimulation unit as a pair of forceps. A circular probe with a diameter of $6 \mathrm{~mm}$ (area $28 \mathrm{~mm}^{2}$ ) was applied upon the dorsum of the second phalanx of the third finger of both hands and the third toe of both feet. The pressure application rate was $1.1 \mathrm{~N} / \mathrm{s}$ (27).

When subjects perceived that the pressure exerted by the forceps changed into a painful stimulus, they activated a button. The pressure was given in kilopascals on a digital display kept out of sight of the subjects. Three consecutive measurements 


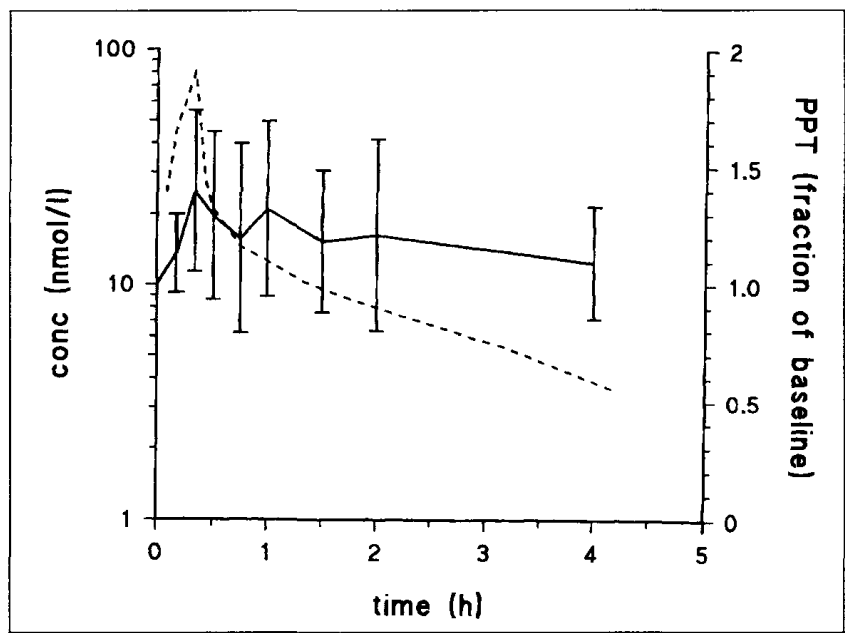

Figure 1) Average median values of pressure pain thresholds (-) (PPT) $( \pm \mathrm{SD})$ in the right third finger given as fraction of baseline values and concomitant mean plasma concentrations of hydromorphone (- - -) (conc) following intravenous administration of $2 \mathrm{mg}$ hydromorphone given over 20 mins

separated by 10 to $15 \mathrm{~s}$ were made. The median value of the three measurements at each location was used. Blood samples were drawn into heparinized glass vacuum tubes (Vacutainer; Becton Dickinson, Stockholm, Sweden), which were placed in ice water and subsequently centrifuged at $4^{\circ} \mathrm{C}, 1500 \mathrm{~g}$, for 10 mins. The plasma was then separated and frozen.

\section{SAMPLE ANALYSIS}

Plasma samples were assayed for hydromorphone in an automated solid phase extraction equipment (ASPEC; Gilson, Villiers, France) coupled on-line to an ion-pair HPLC. The method of analysis was modified from a procedure described earlier for analysis of morphine $(28,29)$. The standards, controls and samples, each $1 \mathrm{~mL}$, were mixed with $100 \mu \mathrm{L}$ of $2 \mu \mathrm{M}$ nalorphine hydrochloride in water (internal standard) and $3 \mathrm{~mL} 0.5 \mathrm{mM}$ ammonium sulphate adjusted to $\mathrm{pH} 9.3$ with ammonia. This sample was passed through the first of two $1 \mathrm{~mL} \mathrm{Sep-Pak} \mathrm{C18}$ columns (100 mg, Waters, Massachusetts) activated with $1 \mathrm{~mL}$ methanol. The cartridges were washed with $5 \mathrm{~mL} 5 \mathrm{mM}$ ammonium sulphate adjusted to $\mathrm{pH} 9.1$ with ammonia, and $0.5 \mathrm{~mL}$ Milli-Q water (Millipore, Massachusetts). Hydromorphone and the internal standard were eluted with $1.25 \mathrm{~mL}$ of a $15 \%$ acetronitrile solution in $10 \mathrm{mM}$ sodium phosphate buffer, $\mathrm{pH} \mathrm{2.1.} \mathrm{The}$ eluate was mixed with $6 \mathrm{~mL}$ of the $0.5 \mathrm{M}$ ammonium buffer and was used to treat the second Sep-Pak C18 cartridge in the same manner as the first one, except that the elution was performed with $0.55 \mathrm{~mL}$ of a $30 \%$ acetonitrile solution in $10 \mathrm{mM}$ sodium phosphate buffer. Before injection on the chromatographic system, $50 \mathrm{~mL} 0.13 \mathrm{M}$ sodium dodecyl sulphate (SDS) was added to the eluate. Nearly all the eluate $(500 \mu \mathrm{L})$ was injected on the analytical column.

Separation was achieved with reversed phase ion-pair HPLC with a Spherisorb ODS $2150 \times 4.6 \mathrm{~mm}$ analytical column $(3 \mu \mathrm{m}$ particles, Jones Chromatography; Hengoed, United Kingdom). The mobile phase was a $10 \mathrm{mM}$ sodium dihydrogen phosphate buffer adjusted to $\mathrm{pH} 2.3$ containing $7 \mathrm{mM}$ SDS and $30 \%$ ace- tonitrile. The flow rate was $1.0 \mathrm{~mL} / \mathrm{min}$, and the column was kept at $30^{\circ} \mathrm{C}$. Detection was made with a $5100 \mathrm{~A}$ Coulochem detector with a 5010 detector cell (ESA, Massachusetts) at $0.44 \mathrm{~V}$. Hydromorphone and the internal standard nalorphine eluted at 22 and 31 mins, respectively. No interfering peaks were detected from blank plasma samples.

The ratios of the peak heights of hydromorphone to internal standard were used to obtain a calibration curve from standards prepared with known concentrations of hydromorphone in donor plasma. Linear least square regression was used for the calculations. Controls and samples were compared with the calibration curve achieved in the same series.

The lower limit of quantification was $2 \mathrm{nmol} / \mathrm{L}$ for hydromorphone. Interassay coefficients of variation for concentrations of 5 and $50 \mathrm{nmol} / \mathrm{L}$ were $8.2 \%$ ( $\mathrm{n}=40$, the present findings were part of a larger study) and $4.2 \%(n=10)$, and intra-assay coefficient of variation were $6.1 \%$ and $1.6 \%$, respectively $(n=10)$.

\section{DATA ANALYSIS}

Plasma hydromorphone concentrations were fitted by a twocompartment model using PCNONLIN (version 3.0) (SCI Software, Kentucky). Estimates of clearance, volume of distribution, mean residence time and terminal elimination half-life were calculated by standard methods.

\section{STATISTICAL CALCULATIONS}

The results are presented as mean $\pm \mathrm{SD}$ or as $95 \% \mathrm{CI}$. A two-tailed $t$ test for paired samples was used for comparisons and the level of significance was set at $5 \%$.

\section{RESULTS}

Oxygen saturation remained normal throughout the procedure. Intravenous infusion of $2 \mathrm{mg}$ hydromorphone caused sensations of fatigue, heaviness and drowsiness in all volunteers. Two volunteers experienced dizziness. Pruritus, generalized or localized to the eyes and face, was reported by eight subjects. Pruritus was most prominent immediately after the infusion and up to 2 or $3 \mathrm{~h}$ after drug administration; it then gradually disappeared. No medical intervention was required.

Analgesic effects (mean results): PPTs were augmented in most subjects immediately after intravenous infusion of hydromorphone. The average median value of PPTs measured in the fingers and toes was significantly higher for 1 and $2 \mathrm{~h}$, respectively, after the start of the infusion. In some subjects, a decrease in pain thresholds compared with baseline was observed later during the treatment. The average of all subjects' median values of PPT in the right finger is given as a fraction of baseline values in Figure 1 together with mean plasma hydromorphone concentrations. Curves for PPTs measured in the left finger and in the right and left toes were similar and are not shown. Interindividual variability in the analgesic effect on PPT (Figure 1) was larger than the variability observed in the studied nonanalgesic effects (Figures 2-4). The analgesic effect, measured as PPT increase, appeared to be well correlated to the measured plasma concentrations of hydromorphone. The analgesic effect had a shorter duration than the nonanalgesic effects on saliva production and pupil size. A significant increase of PPT compared with baseline 


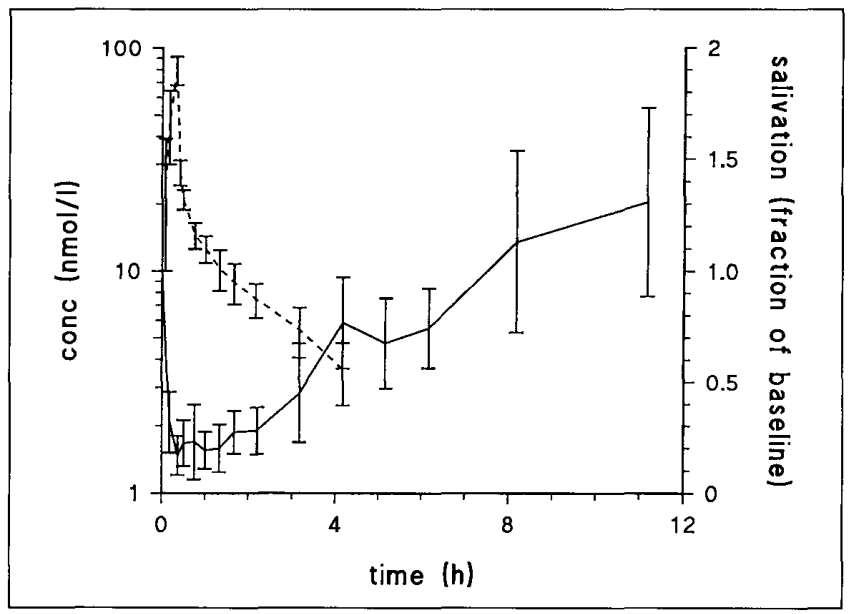

Figure 2) Mean saliva production ( - ) given as fraction of baseline $( \pm$ SD) and mean plasma concentrations of hydromorphone (- - -) (conc) $( \pm$ SD) following intravenous administration of $2 \mathrm{mg}$ hydromorphone over 20 mins

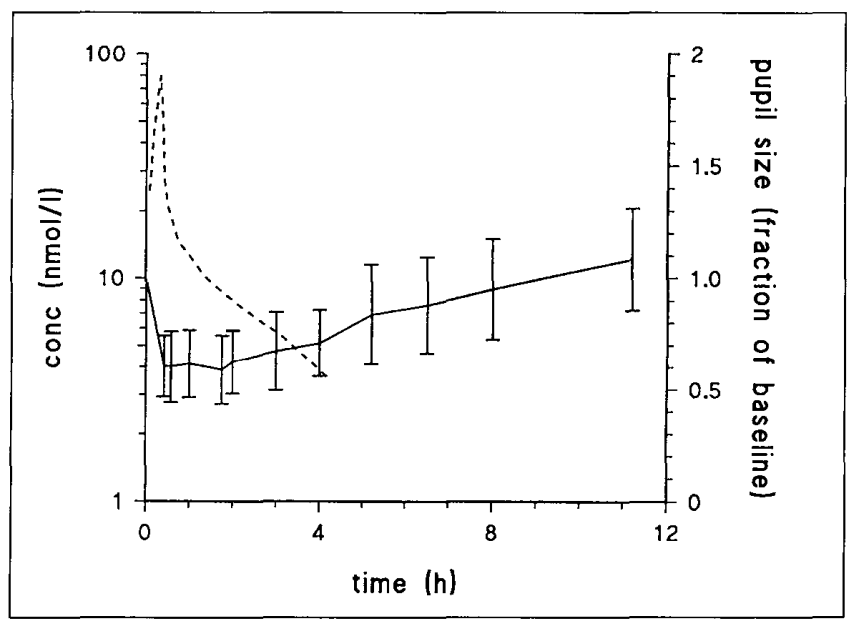

Figure 3) Mean pupil size ( - ) given as fraction of baseline values ( \pm SD) and concomitant mean plasma concentrations of hydromorphone (- - -) (conc) following intravenous administration of $2 \mathrm{mg}$ hydromorphone over 20 mins

was registered up to $2 \mathrm{~h}$ following intravenous infusion of hydromorphone. Mean plasma concentration of hydromorphone at $2 \mathrm{~h}$ was $8.9 \pm 1.9 \mathrm{nmol} / \mathrm{L}(95 \%$ CI 7.7 to 10.1$)$.

Nonanalgesic effects (mean results) - Salivation and miosis: Saliva production was significantly $(\mathrm{P}<0.0001)$ decreased after intravenous infusion of hydromorphone was started compared with baseline values, and remained significantly reduced for $6 \mathrm{~h}$ after the end of the infusion. Mean saliva production $( \pm S D)$ and mean plasma concentrations of hydromorphone ( \pm SD) following intravenous administration of $2 \mathrm{mg}$ hydromorphone are shown in Figure 2.

Mean pupil size was found to be significantly $(\mathrm{P}<0.0001)$ decreased at the first measurement 26 mins after the infusion and remained significantly smaller than initial size up to $5 \mathrm{~h}$ following intravenous infusion of hydromorphone (Figure 3).

Central nervous system effects: Central nervous system (CNS) effects were common after infusion of hydromorphone. The
TABLE 1

Number of healthy subjects experiencing any measure of the six studied effects following $2 \mathrm{mg}$ hydromorphone given as an intravenous infusion over $\mathbf{2 0}$ mins

Time (mins after the start of the infusion)

\begin{tabular}{lllllll} 
Effect $\quad 0-60$ & $60-130$ & $130-250$ & $250-370$ & $370-670$ & $670-1800$ \\
\hline
\end{tabular}

\begin{tabular}{lrrrrrr} 
Dysphoria & 3 & 4 & 3 & 4 & 2 & 1 \\
Euphoria & 9 & 8 & 8 & 5 & 4 & 6 \\
Fatigue & 12 & 12 & 12 & 12 & 8 & 5 \\
Headache & 5 & 4 & 7 & 9 & 10 & 6 \\
Nausea & 5 & 5 & 5 & 3 & 4 & 2 \\
Heaviness & 12 & 12 & 11 & 8 & 7 & 5 \\
\hline
\end{tabular}

$n=12$

\section{TABLE 2}

Pharmacokinetic parameters obtained from the PCNONLIN analysis of plasma concentrations of hydromorphone and mean values $( \pm S D$ and $95 \% \mathrm{Cl}$ ) in 12 healthy volunteers after intravenous infusion of $2 \mathrm{mg}$ hydromorphone over 20 mins

\begin{tabular}{|c|c|c|c|c|}
\hline \multirow[b]{2}{*}{ Parameter } & & \multirow[b]{2}{*}{ Mean \pm SD } & \multicolumn{2}{|c|}{$95 \% \mathrm{Cl}$} \\
\hline & & & Lower & Upper \\
\hline Hybrid constant alpha & $h^{-1}$ & $10.4 \pm 4.1$ & 7.7 & 13 \\
\hline Hybrid constant beta & $h^{-1}$ & $0.39 \pm 0.08$ & 0.34 & 0.44 \\
\hline Terminal half-life & $\mathrm{h}$ & $1.87 \pm 0.40$ & 1.61 & 2.13 \\
\hline Systemic clearance & $\mathrm{L} / \mathrm{min}$ & $1.81 \pm 0.25$ & 1.65 & 1.97 \\
\hline $\begin{array}{l}\text { Volume of distribution } \\
\text { during the beta-phase }\end{array}$ & $\mathrm{L} / \mathrm{kg}$ & $4.15 \pm 0.86$ & 3.60 & 4.7 \\
\hline $\begin{array}{l}\text { Volume of distribution } \\
\text { at steady-state }\end{array}$ & $\mathrm{L} / \mathrm{kg}$ & $3.08 \pm 0.60$ & 2.70 & 3.47 \\
\hline $\begin{array}{l}\text { Volume of central } \\
\text { compartment }\end{array}$ & $\mathrm{L} / \mathrm{kg}$ & $0.61 \pm 0.27$ & 0.43 & 0.78 \\
\hline Mean residence time & $h$ & $2.02 \pm 0.50$ & 1.70 & 2.34 \\
\hline
\end{tabular}

number of subjects experiencing any measure of the six studied effects are given in Table 1. Heaviness and fatigue were reported by all subjects. Nausea was persistent in five subjects and occurred during or after the infusion, and two of the female subjects vomited. Dysphoria was present in subjects who were also nauseated. Euphoria, defined as a sense of well-being, was more common early during the treatment, then gradually decreased and was often followed by headache. Consequently, headache was more frequent later during the treatment, 4 to $11 \mathrm{~h}$ after the end of the infusion.

Pharmacokinetics: Mean plasma concentrations of hydromorphone are given in Figures 1 to 3. Standard deviations are given in Figure 2. Hydromorphone could be measured in plasma up to between 4 and $8 \mathrm{~h}$ after the start of intravenous infusion. At later sampling times, the plasma levels of the drug were below the limits of quantification. Pharmacokinetic parameters are given in Table 2. 


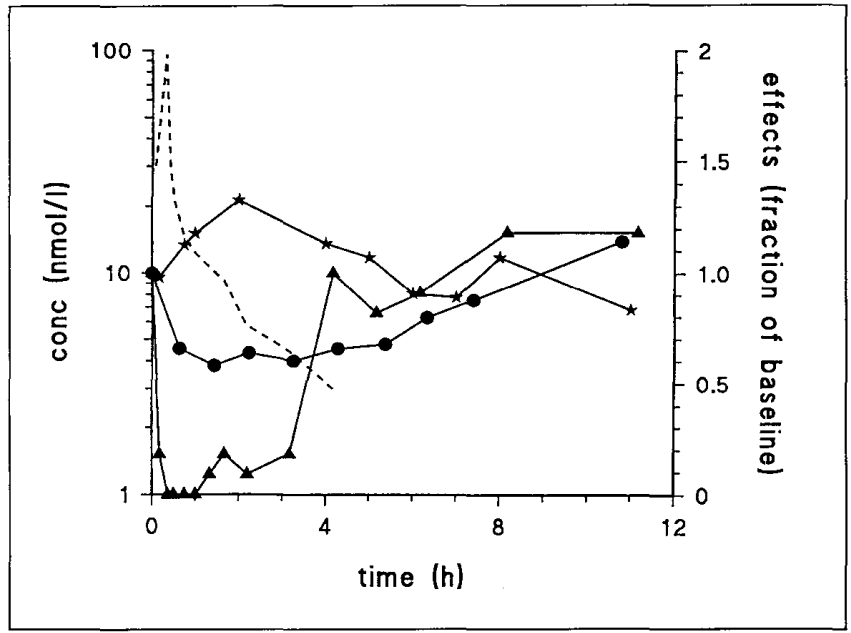

Figure 4a) Individual median values of pressure pain thresholds (PPT, $\star$ ) measured in the right finger, saliva production $(\boldsymbol{\Lambda})$ and pupil size $(\boldsymbol{O})$ given as fraction of baseline ( \pm SD) for subject 3 . Values had little effect on PPT despite considerable nonanalgesic effects. conc Individual plasma concentrations of hydromorphone (- - -) following intravenous infusion over 20 mins of 2 mg hydromorphone

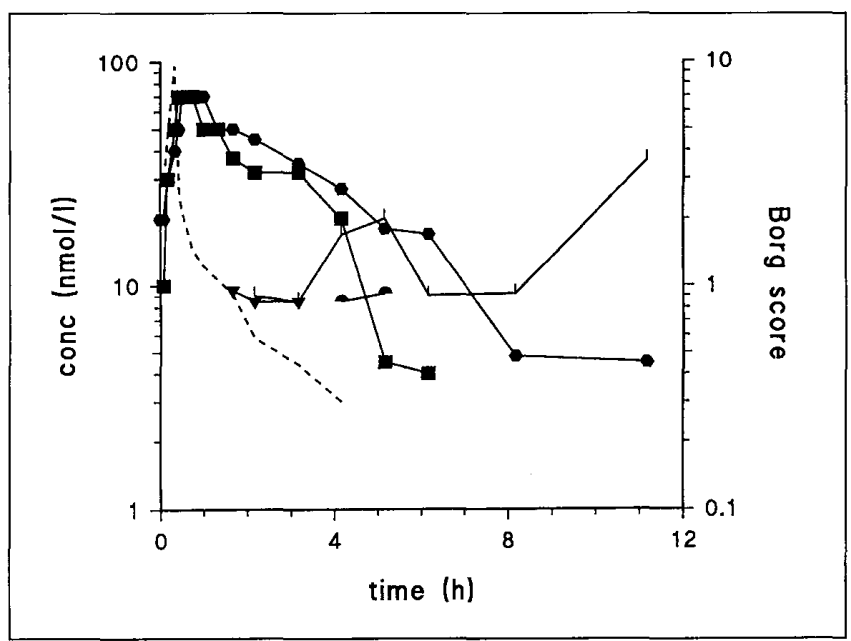

Figure 4b) Individual scores of euphoria (lower half of circle), dysphoria (upper half of circle), nausea ( $\mathbf{\nabla})$, headache $(\mid)$, fatigue (hexagon) and heaviness $(\square)$ for subject 3. conc Individual plasma concentrations of hydromorphone (-. -) following intravenous infusion over 20 mins of $2 \mathrm{mg}$ hydromorphone

Individual results: In some individuals the effect of hydromorphone on PPTs was relatively small (eg, subject 3 ) despite considerable CNS effects and a decrease in pupil size and saliva production (Figures $4 a, 4 b$ ). In other subjects there was a strong accordance between analgesic and nonanalgesic effects (eg, subject 5). In Figure 4 individual data are given for these representative subjects. Median values of PPTs measured in the right finger, values of saliva production and pupil size are shown as fraction of baseline values. Individual scores of the studied CNS effects and concomitant plasma concentrations of hydromorphone are also given for subjects 3 and 5 , respectively.

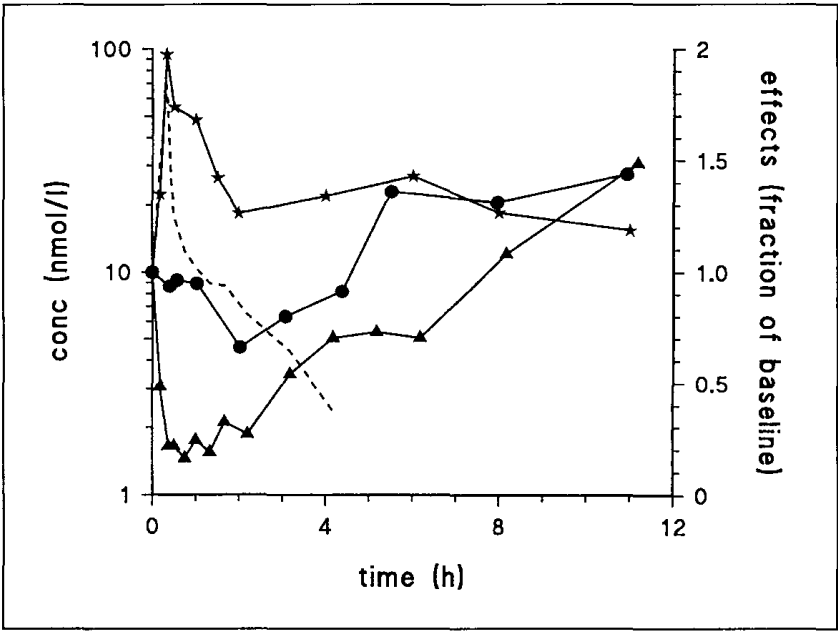

Figure 4c) Individual median values of pressure pain thresholds (PPT, $\star$ ) measured in the right finger, saliva production $(\boldsymbol{\Delta})$ and pupil size $(\boldsymbol{O})$ given as fraction of baseline $( \pm$ SD) for subject 5 . There was high correlation between analgesic and nonanalgesic effects of hydromorphone. conc Individual plasma concentrations of hydromorphone (- - -) following intravenous infusion over 20 mins of $2 \mathrm{mg}$ hydromorphone

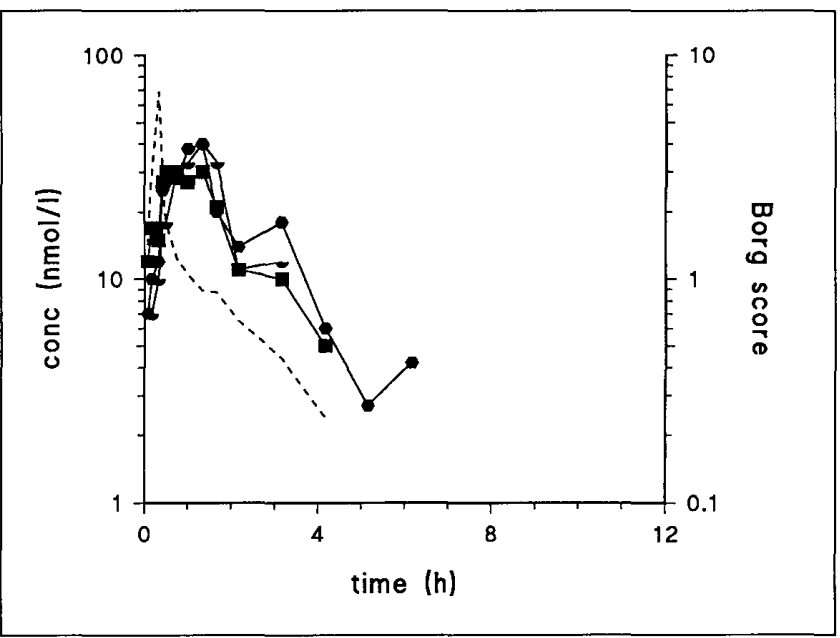

Figure 4d) Individual scores of euphoria (lower half of circle), dysphoria (upper half of circle), nausea $(\mathbf{\nabla})$, headache (|), fatigue (hexagon) and heaviness $(\square)$ for subject 5 . conc Individual plasma concentrations of hydromorphone (- - -) following intravenous infusion over 20 mins of $2 \mathrm{mg}$ hydromorphone

\section{DISCUSSION}

Analgesic and nonanalgesic effects of hydromorphone, such as miosis, dry mouth and CNS effects, were systematically evaluated in the present study. The short duration of analgesia, measured as increase of PPT, corresponds to the findings of Coda et al (9) and the absent analgesic effects at the lower plasma concentrations agree with the results of Reidenberg et al (30). The larger variability of the effect of hydromorphone on PPT compared with the variability observed in the nonanalgesic effects may reflect the well known interindividual variability of analgesic effect of a standard dose of an opioid (6).

The observed later increase of the sensitivity for pain in our 
volunteers may have been caused by the repeated measurements, thus resulting in little change or even decrease of PPT compared with baseline values and preventing identification of a true analgesic effect of hydromorphone. This interpretation is contradicted by the results of Brennum and colleagues (27), who used the pressure algometer to measure PPT in fingers and toes of healthy volunteers. They reported that repeated measurements were stable within the same individual with an intra-individual coefficient of variation of $14 \%$. However, our measurements of PPT displayed larger coefficients of variation than those reported by Brennum et al (27). This variability may have been caused by the CNS effects, such as fatigue, which may have caused problems for the subjects to identify a discrete change in PPT. Interindividual coefficients of variation for PPT also vary between studies $-30 \%$ to $45 \%$ according to Brennum et al (27). Male subjects had $50 \%$ higher values for PPT compared with female subjects in their study (27). In our study, each volunteer acted as his or her own control because the values were compared with baseline measurements before drug infusion, and interindividual variability of the predose values can therefore be disregarded. PPT may be a convenient and safe method of determining changes in pressure pain perception, but the influence of environment and drug effects on CNS complicates the interpretation of the results.

Nonanalgesic effects of hydromorphone were also found to be well correlated to plasma concentrations of the drug. Saliva production was significantly reduced for more than $6 \mathrm{~h}$ following intravenous administration of hydromorphone. The inhibiting effect on saliva production was more pronounced and of longer duration compared with the reduction seen after intravenous infusion of $10 \mathrm{mg}$ of morphine $(23,31)$. Dry mouth was a common complaint during opioid therapy (32), but the mechanism for reduction of saliva production induced by morphine (25) and, as we have now shown, by hydromorphone, is unknown. Opioids are known to induce changes in the production of various secretions from the gastrointestinal tract due to stimulation of peripheral opioid receptors (33). The effect of opioids on the salivary glands, however, is neither discussed in the extensive review of Kromer (33) nor mentioned in textbooks (6).

Reduction of pupil size is a well known clinical sign occurring after opioid administration. Miosis is caused by cut-off cortical inhibition of the Edinger-Westphal nuclei (34) and is mediated through stimulation of mu and kappa opioid receptors (6). Measurement of pupil size is a convenient method for assessment of opioid receptor stimulation, but has only minor clinical importance. Photographic methods to assess pupil size are regarded as accurate (35) and were used by Inturrisi et al (36), Miller et al (37), Strain et al (38) and Westerling et al $(23,25)$ to evaluate miosis following opioid administration.

Significant reduction of the pupil size was measured on the first photograph taken 6 mins after the end of intravenous infusion of hydromorphone, and the pupils remained significantly reduced (compared with initial size) for $5 \mathrm{~h}$ after the end of the infusion. Compared with the miosis observed and measured with the same method after intravenous morphine administration (23), the reduction of pupil size was of shorter duration following hydromorphone administration although the maximal miosis was of similar magnitude.
CNS effects were pronounced during and after hydromorphone infusion. Heaviness and fatigue were closely related to the obtained plasma concentrations of hydromorphone. Euphoria may have been an expected side effect in this open study, whereas the subjects would not have been expected to anticipate sensations of heaviness, which we have earlier found to correlate well with plasma morphine concentrations $(23,25)$. Nausea, which was persistent in the subjects affected, and dysphoria were, not surprisingly, related. Euphoria and nausea did not coincide.

Our opioid-naive subjects displayed considerable CNS effects following the single dose of hydromorphone. However, patients with long term opioid intake often develop tolerance to CNS effects like fatigue, but not to other side effects like nausea and constipation.

Hydromorphone has been considered to be less often associated with pruritus than morphine (39). Pruritus was a common complaint in this study whereas the spontaneously reported incidence of itching was low or absent in similar studies where morphine was given intravenous to healthy subjects $(23,25,31)$.

The value of terminal half-life $(1.87 \pm 0.4 \mathrm{~h}, 95 \% \mathrm{CI} 1.61$ to 2.13 ) found in the present study was shorter than that reported by Hill and co-workers (7). Our subjects received a standard dose of $2 \mathrm{mg}$ hydromorphone ( 25 to $37 \mu \mathrm{g} / \mathrm{kg}$ body weight), whereas the volunteers in the study of Hill et al (7) were given 10, 20 and $40 \mu \mathrm{g}$ hydromorphone $/ \mathrm{kg}$ body weight as bolus injections at three separate occasions. Systemic clearance for hydromorphone was slightly lower in our study than reported by Hill et al (7), and they found higher values for volume of distribution. Hill et al (7) fitted their plasma concentrations to a three-compartment model, which may explain some of the differences of the pharmacokinetic variables found in the two studies. A three-compartment model will give a longer terminal half-life because the initial fast changes in plasma concentration of the drug are fitted to the first two phases in the model and therefore have less influence on the terminal slope of the curve.

\section{CONCLUSIONS}

Intravenous infusion of $2 \mathrm{mg}$ hydromorphone to 12 opioid-naive subjects produced immediate analgesic and nonanalgesic effects, measured as an increase of PPT and reduced saliva production and miosis, respectively. Fatigue and heaviness were reported by all subjects in this open study, whereas nausea was present in five. Eight subjects suffered from pruritus. The duration of the nonanalgesic effects were several hours longer than the analgesic effect, assessed by PPT, of the drug. The plasma concentrations of hydromorphone appeared to be well correlated to the studied effects.

ACKNOWLEDGEMENTS: This study was supported by grants from G, A och E Nilssons Stiftelse för bekämpning av cancersjukdomar, Stiftelsen Claes Groschinskys Minnesfond and by the Medical Faculty of the University of Lund, Sweden.

\section{REFERENCES}

1. World Health Organization. Cancer pain relief and palliative care. Geneva: WHO, Technical report series 804, 1990.

2. Sjögren P, Jonsson T, Jensen N-H, Drenck NE, Jensen TS. Hyperalgesia and myoclonus in terminal cancer patients treated with continuous intravenous morphine. Pain 1993;55:93-7. 
3. Sjögren P, Dragged L, Christensen CB. Myoclonic spasms during treatment with high doses of intravenous morphine in renal failure. Acta Anaesth Scand 1993;37:780-2.

4. Sjögren P, Eriksen J. Opioid toxicity. Curr Opin Anaesthesiol 1994;7:465-9.

5. Sjögren P, Jensen N-H, Jensen TS. Disappearance of morphine-induced hyperalgesia after discontinuing or substituting morphine with other opioid agonists. Pain 1994;59:313-6.

6. Jaffe JH, Martin WR. Opioid analgesics and antagonists. In: Goodman Gilman A, Rall TW, Nies AS, Taylor P, eds. The Pharmacological Basis of Therapeutics, 8th edn. New York: Pergamon Press Inc, 1990:485-521.

7. Hill HF, Coda BA. Tanaka A, Schaffer R. Multiple-dose evaluation of intravenous hydromorphone pharmacokinetics in normal human subjects. Anesth Analg 1991;72:330-6.

8. Chen ZR, Irvine RJ, Somogyi AA, Bochner F. Mu receptor binding of some commonly used opioids and their metabolites. Life Sci 1991;48:2165-71.

9. Coda B, Tanaka A, Hill H, Iverson K. Dose effects of hydromorphone in human analgesia. Pain 1990;Suppl 5:188. (Abst)

10. Keeri-Szanto M. Anaesthesia time/dose curves IX: The use of hydromorphone in surgical anaesthesia and postoperative pain relief in comparison to morphine. Can J Anaesth 1976;23:587-95.

11. Mahler DL, Forrest WH Jr. Relative analgesic potencies of morphine and hydromorphone in postoperative pain. Anesthesiology 1975:42:602-7.

12. Hays H, Mayo P. A single case study using high-dose hydromorphone to control severe pain and serial psychometric testing to assess effects. J Pain Symptom Manage 1993;8:173-6.

13. Bruera E, Brenneis $C$, Michaud M, et al. Use of the subcutaneous route for the administration of narcotics in patients with cancer pain. Cancer 1988;62:407-11.

14. Moulin DE, Kreeft JH, Murray-Parsons N, Bouquillon AI. Comparison of continuous subcutaneous and intravenous infusions for management of cancer pain. Lancet 1991:337:465-8.

15. Searle NR, Roy M, Bergeron G, et al. Hydromorphone patient-controlled analgesia (PCA) after coronary artery bypass surgery. Can J Anaesth 1994;41:198-205.

16. Urquhart ML, Klapp K, White PF. Patient-controlled analgesia: a comparison of intravenous versus subcutaneous hydromorphone. Anesthesiology 1988;69:428-32.

17. Inturrisi CE, Colburn WA, Kaiko RF, Houde RW, Foley KM. Pharmacokinetics and pharmacodynamics of methadone in patients with chronic pain. Clin Pharmacol Ther 1987;41:392-401.

18. Eisele JH, Grigsby EJ, Dea G. Clonazepam treatment of myoclonic contractions associated with high-dose opioids: case report. Pain 1992;49:2312.

19. Babul N, Darke AC. Putative role of hydromorphone metabolites in myoclonus. Pain 1992;51:260-1. (Lett)

20. Vallner JJ, Stewart JT, Kotzan JA, Kirsten EB, Honigberg IL. Pharmacokinetics and bioavailability following intravenous and oral administration to human subjects. J Clin Pharmacol 1981;21:152-6.

21. Borg G. A category scale with ratio properties for intermodal and interindividual comparisons. In: Geissler HG, Petzold P, eds.
Psychophysical judgment and the process of perception. Berlin: VEB Deutscher Verlag der Wissenschaften, 1982:25-34.

22. Borg G, Holmgren A, Lindblad I. Quantitative evaluation of chest pain. Acta Med Scand 1981;644:43-5.

23. Westerling D, Höglund P, Lundin S, Svedman P. Transdermal administration of morphine to healthy subjects. Br J Clin Pharmac 1994:37:571-6.

24. Heinize U, Birkhed D, Björn H. Secretion rate and buffer effect of resting and stimulated whole saliva as a function of age and sex. Swed Dent J 1983;7:227-38.

25. Westerling D, Persson C, Höglund P. Plasma concentrations of morphine, morphine-3-glucuronide, and morphine-6-glucuronide after intravenous and oral administration to healthy volunteers: Relationship to nonanalgesic actions. Ther Drug Monitor 1995;17:287-301.

26. Marks LE, Borg G, Ljunggren G. Individual differences in perceived exertion assessed by two new methods. Percept Psychophys 1983;34:280-8.

27. Brennum J, Kjeldsen M, Jensen K, Jensen TS. Measurement of human pressure-pain thresholds on fingers and toes. Pain 1989;38:211-7.

28. Svensson JO, Rane A, Säwe J, Sjöqvist F. Determination of morphine, morphine-3-glucuronide and (tentatively) morphine-6-glucuronide in plasma and urine using ion-pair high-performance liquid chromatography. J Chromatogr 1982;230:427-32.

29. Svensson JO. Determination of morphine, morphine-6-glucuronide and normorphine in plasma and urine with high-performance liquid chromatography and electrochemical detection. J Chromatogr 1986;375:174-8.

30. Reldenberg MM, Goodman H, Erle H, et al. Hydromorphone levels and pain control in patients with severe chronic pain. Clin Pharmacol Ther 1988;44:376-82.

31. Westerling D, Frigren L, Höglund P. Morphine pharmacokinetics and effects on salivation and continous reaction times in healthy volunteers. Ther Drug Monitor 1993;15:364-74.

32. White ID, Hoskin PJ, Hanks GW, Bliss JM. Morphine and dryness of the mouth. BMJ 1989;298:1222-3.

33. Kromer W. Endogenous and exogenous opioids in the control of gastrointestinal mothity and secretion. Pharmacol Rev 1988;40:121-62.

34. Thompson HS. The pupil. In: Hart WM Jr, ed. Adler's Physiology of the Eye: Clinical Application. Malvern: Mosby-Year Book, Inc, 1992:422.

35. Turner $P$. The human pupil as a model for clinical pharmacological investigations. J R Coll Physicians Lond 1975;9:165-71.

36. Inturrisi C, Portency R, Stillman M, Colburn W, Foley K. Hydromorphone bioavailability and pharmacokineticpharmacodynamic (PK-PD) relationships. Clin Pharmacol Ther 1988;43:162. (Abst)

37. Miller CD, Asbury AJ, Brown JH. Pupillary effects of alfentanil and morphine. Br J Anaesth 1990;65:415-7.

38. Strain EC, Preston KL, Liebson IA, Bigelow GE. Acute effects of buprenorphine, hydromorphone and naloxone in methadonemaintained volunteers. J Pharmacol Exp Ther 1992;261:985-93.

39. Houck CS, Troshynski T, Berde CB. Treatment of pain in children. In: Wall PD, Melzack R, eds. Textbook of Pain, 3rd edn. London: Churchill Livingstone, 1994:1422. 


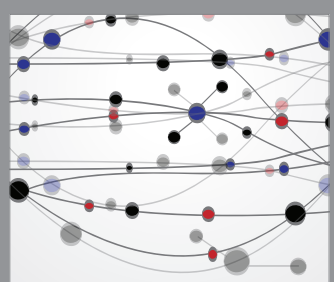

The Scientific World Journal
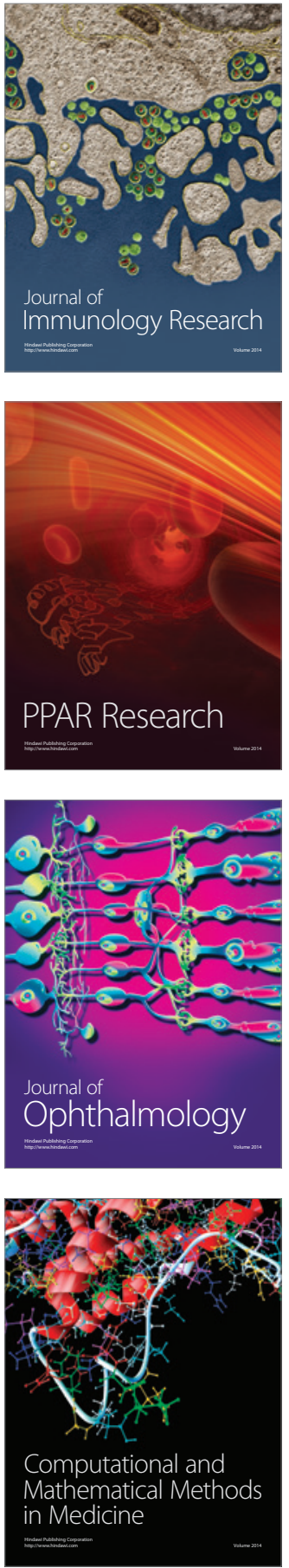

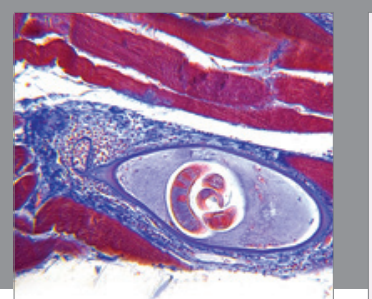

Gastroenterology Research and Practice

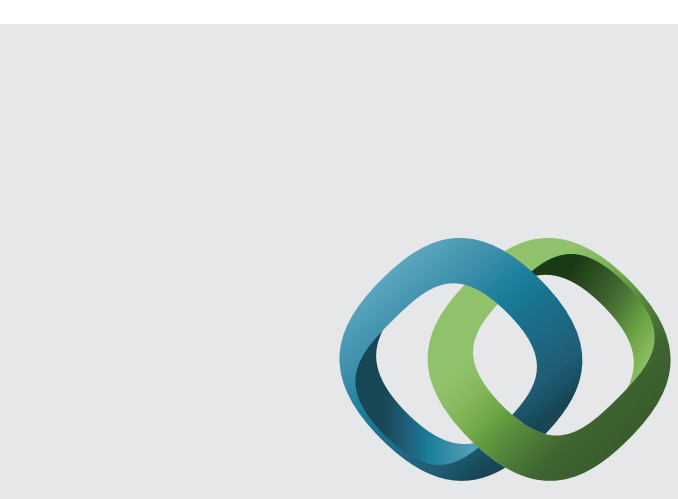

\section{Hindawi}

Submit your manuscripts at

http://www.hindawi.com
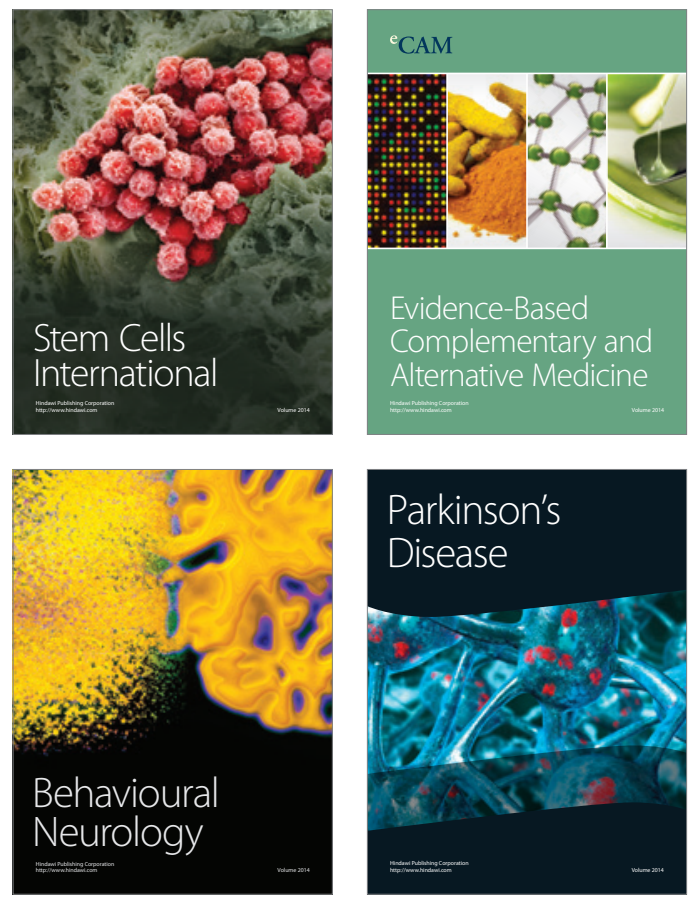
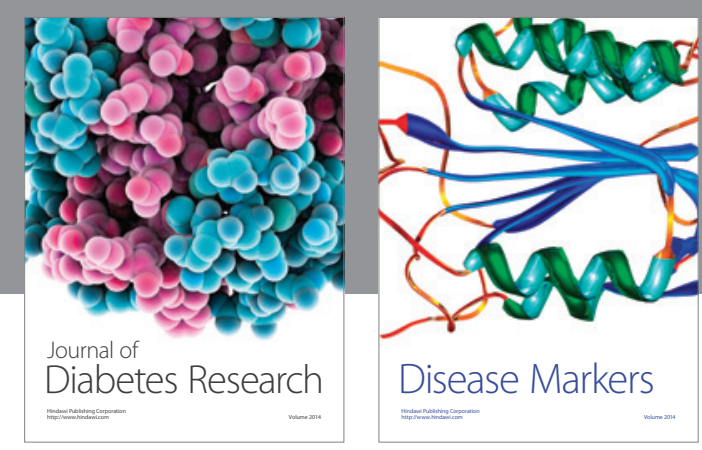

Disease Markers
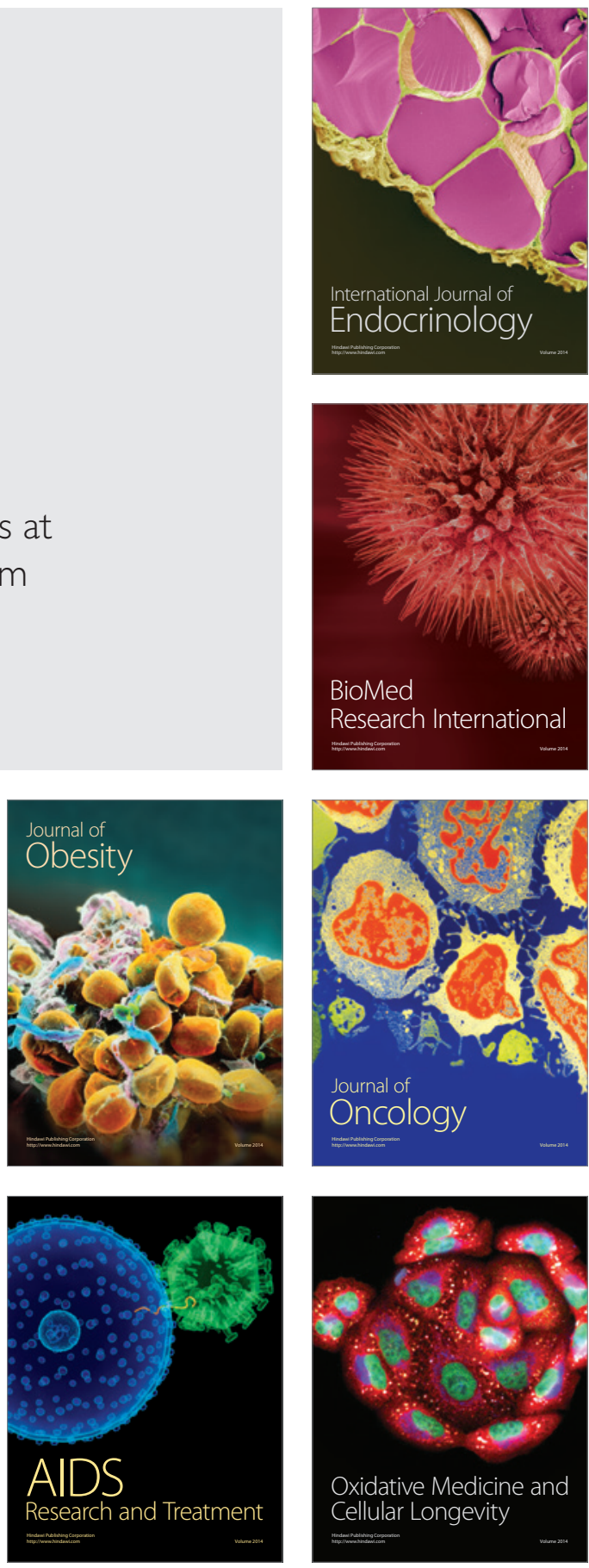